\title{
Richard Cords †
}

Richard Cords ist tot. Am 22. I. 1931 ist er, erst 48 Jahre alt, von uns gegangen. Die deutsche Ophthalmologie ist um eine Erfüllung ärmer geworden. Von Ewald Bering, dem großen Physiologen, und von Hubert, Satiler, dem Kliniker in Leipz' 'g, wurde Cords in die wissenschaftliche Arbeit eingeführt. Bei Hermann Kuhnt in Bonn, dessen Assistent er in den Jahren 1910 bis 1918 war, wurde er zum vollendeten Kliniker und zu einem guten Operateur. Dozent an der Universität Bonn seit 1911. In der Kriegszeit wirkte er in Feldlazaretten. Aus reicher Erfahrung heraus schrieb er: ,,Augenärzlliche Er††ahrungen über Schädelschüsse im Kriege", eine der besten Publikationen aus dieser Zeit.

Seit 1919 war Cords, unter Prof. Pröbsling, doch in selbständiger Tätigkeit, Leiter einer der neuen Universität Koln angeglieclerten Augen-abteilung in der großen Krankenanstalt KölnLindenburg. Flier fand er das ideale und speziell ihm gemäße Feld seines Wirkens: in naher Zusammenarbeit mit Internen, Neurologen, Otiatern und Chirurgen wissen-scha.ftlich und praktisch zu arbeiten.

In den letzten drei Jahren verwaltete er im Auftrage des Mini-steriums für den emeritierten Ordinarius Prof. Pröbsting das Fach der Augenheilkunde und beide Abteilungen der Augenklinik in Köln.

Wir alle kennen die Frucht seiner wissenschaftlichen Arbeit aus dieser Zeit, die alle Gebiete

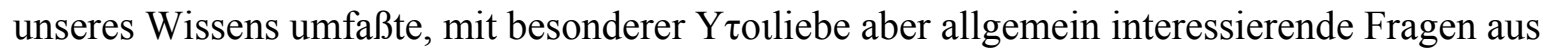
dem Grenzgebiet mit Neurologie betraf. Auf jeder Tagung der D. Ophth. Ges. hörten wir einen stets aktuelle Fragen behandelnden Beitrag von Cords. Wir hörten die Art seines Vortrages, wir lernten seine sympathische Persönlichkeit ken-ne $\alpha$ und alle glaubten: Hier reift ein Meister unseres Faches heran.

Sein literarisches Meisterstück wurde die soeben erst erschienene um-fassende Bearbeitung der ,,Pathologie der Augenbewegunÿ,eri' im neuen Handbuch der Ophthalmologie mit alien ihren schwierigen, ihm aber wohl-vertrauten Fragen, die Cords insbesondere bezüglich aller Formen des Nystagmus durch eigene Forschungen poitiv gefördert hat.

Dieses Denkmal erfolgreicher Arbeit vor allem überlebt ihn und wird nodi lange ein Markstein unseres Wissens sein. Bleibenden Wert haben auch viele von seinen zahlreichen sonstigen Publikationen. Auch einer der markantesten Fälle von scheibenjörmiger Entatung der Netzhaulmille, der in die Monographie über diese Krankheit aufgenommen ist, wurde vorwiegend von R. Cords in der Bonner Klinik mit feinem Verstänclnis beobachtet. 332

Richard Cords $\uparrow$.

Man sollte $\mathrm{m}>$ einen, daß solchem Wirken, das 20 Jahre hindurch konsequent und mit Erfolg in der Arbeit auf das höchste akademische Ziel eingestellt war, im reifen Mannesalter auch ein der Leistung ent-sprechender Lohn beschieden ware. Wir wissen, daß es tragischerweise nicht der Fall war.

Andere und Jüngere wurden ausgewählt, als die Besetzung deutscher Ordinariate in den letzten Jahren in Betracht kam. Cords selbst war bei allem Ernst und einer gewissen Schwere seines 
Wesens in dieser Hinsicht ein unentwegter und gläubiger Optimist. Jahrelang konnte inn keine Enttäuschung davon abhalten, fest daran zu glauben, daß der Wert seiner Leistung schlíeßlich doch die gebührende Anerkennung finden müsse. Als dies auch im Jahre 1930 nicht der Fall war und neue Kränkung dazukam, da erst zerbrach er, verzweifelnd an der Gerechtigkeit der Welt, an die er geglaubt hatte. Wer will sich vermessen, da zu richten? -

Ein Grab hat sich geschlossen, ein untadeliger Mann ist iiber Borcl. Man sage nicht, er sei zu weich für dieses harte Leben gewesen.

Niemand wird behaupten können, daß cler glänzende junge E. H. PagenstecJwr, der im Jahre 1918 in einer dunklen Stunde in Trauer iiber das Leid des deutschen Vaterlandes aus dem Leben schied, nicht geeignet gewesen ware, einen Lehrstuhl zu zieren und deutsche Studenten zur Wissenschaft zu erziehen.

Die Wissenschaft braucht Köp†e und Könner. Eine ernste Frage stehtüber cliesem frischen Grabe: Haben wir so viel wertvollen wissenschaft-lichen Nachwuchs in der deutschen Ophthalmologie, daß man diese Hoff-nung zcrschellen lassen konnte? Paul Junius, Bonn. Personalien.

In .hGießen hat sich der Oberarzt der Augenklinik Dr. Walter Rauh habilitiert. 